\title{
Anthropogenic and natural forcing impacts on ENSO-like decadal variability during the second half of the 20th century
}

\author{
Hideo Shiogama, ${ }^{1}$ Masahiro Watanabe, ${ }^{2}$ Masahide Kimoto, ${ }^{3}$ and Toru Nozawa ${ }^{1}$ \\ Received 21 June 2005; revised 28 September 2005; accepted 11 October 2005; published 11 November 2005.
}

[1] Several climate simulations, performed with an atmosphere-ocean coupled general circulation model, are made to evaluate the influences of anthropogenic and natural external forcing on the observed fluctuation of the Decadal El Niño-Southern Oscillation (DENSO) during the second half of the 20th century. A comparison of DENSO in the model simulations and the observations suggests that the observed variability includes an unusually large trend relative to that expected from purely natural variations. Moreover, we show that there is a large probability that this trend is mainly attributable to anthropogenic factors. Citation: Shiogama, H., M. Watanabe, M. Kimoto, and T. Nozawa (2005), Anthropogenic and natural forcing impacts on ENSO-like decadal variability during the second half of the 20th century, Geophys. Res. Lett., 32, L21714, doi:10.1029/2005GL023871.

\section{Introduction}

[2] A number of atmosphere-ocean coupled general circulation models (CGCMs) have been used for future climate simulations of the response to increasing greenhouse gas (GHG) concentrations. Among these CGCMs, many of them predict an El Niño-like warming in the sea surface temperature (SST) in the tropical Pacific, whereas a few suggest the opposite, La Niña-like, SST changes in the 21st century [e.g., Intergovernmental Panel on Climate Change (IPCC), 2001; Yu and Boer, 2002].

[3] In the second half of the 20th century, an El Niño-like SST warming signal has already been observed [Nitta and Yamada, 1989; Parker et al., 1994; Deser et al., 2004]. Several studies suggested that this warming is associated with an upward trend in the low-frequency variability of the atmosphere-ocean system, referred to as El Niño-Southern Oscillation (ENSO)-like decadal (or interdecadal) variability (hereafter DENSO) or Pacific Decadal Oscillation [e.g., Zhang et al., 1997; Mantua et al., 1997; Deser et al., 2004]. While the overall spatial structure of DENSO, such as in SST and sea level pressure anomalies, is similar to ENSO, its dominant timescale is interdecadal [Minobe, 1999].

[4] Previous CGCM studies have shown that DENSO appears even without changes in external forcing, thus suggesting that DENSO is a mode of natural variability in the climate system [e.g., Knutson and Manabe, 1998;

\footnotetext{
${ }^{1}$ National Institute for Environmental Studies, Tsukuba, Japan.

${ }^{2}$ Faculty of Environmental Earth Science, Hokkaido University, Sapporo, Japan. Japan.

${ }^{3}$ Center for Climate System Research, University of Tokyo, Kashiwa,

Copyright 2005 by the American Geophysical Union. 0094-8276/05/2005GL023871\$05.00
}

Yukimoto et al., 2000]. To date there have been several mechanisms proposed which may explain the recent upward trend in the DENSO index. These include: (1) a random chance due to internal variations [Folland et al., 1999]; (2) the influence of external forcing [Knutson and Manabe, 1998; Livezey and Smith, 1999]; (3) a combination of external effects and natural internal variations [Moron et al., 1998]. Using a long-term observational data and an autoregressive moving average method, pioneering work by Trenberth and Hoar [1996] demonstrated that the upward trend of the ENSO-like signal in the recent decades is unusual with respect to the past range of observed fluctuations. This may imply that the changes are partly caused by external factors, in particular increases in the well mixed GHGs.

[5] Recently, several detection and attribution approaches that compare observations and CGCM realizations have been applied to historical data records, such as surface air temperature (SAT) [e.g., Tett et al., 1999], ocean heat content alterations [Barnett et al., 2001], and the trend of the North Atlantic Oscillation (NAO) (see review by Gillett et al. [2003]). By comparing the observed DENSO index trend with that of a CGCM, the present study attempts to statistically test the unusualness of the observed DENSO trend, and the possibility that the observed change is attributable to external causes.

\section{20th Century Climate Simulations}

[6] In our analysis, we use a CGCM called MIROC, developed by the Center for Climate System Research of the University of Tokyo (CCSR), the National Institute for Environmental Studies (NIES), and the Frontier Research Center for Global Change of the Japan Agency for MarineEarth Science and Technology (FRCGC). Our CGCM includes five components: atmosphere, ocean, sea-ice, land, and rivers. A detailed description of MIROC is given in $K-1$ Model Developers [2004]. The spatial resolution of the atmospheric component is T42L20, while the horizontal resolution of the ocean component is $1.4^{\circ}$ in longitude by a variable $0.56-1.4^{\circ}$ in latitude with 44 levels in the vertical $(21$ in the upper $500 \mathrm{~m}$ ). The model requires no flux adjustment.

[7] We perform three types of simulation for the $1850-$ 2000 period forced by historical external factors. The first one includes natural external forcing due to changes in solar irradiance [Lean et al., 1995] and alterations of stratospheric aerosols following volcanic eruptions [Sato et al., 1993]. The second is externally forced by anthropogenic agents, the increase in the GHG concentration [Johns et al., 2003], direct and (first and second) indirect effects due to changes in anthropogenic sulfate and carbon aerosol emissions 


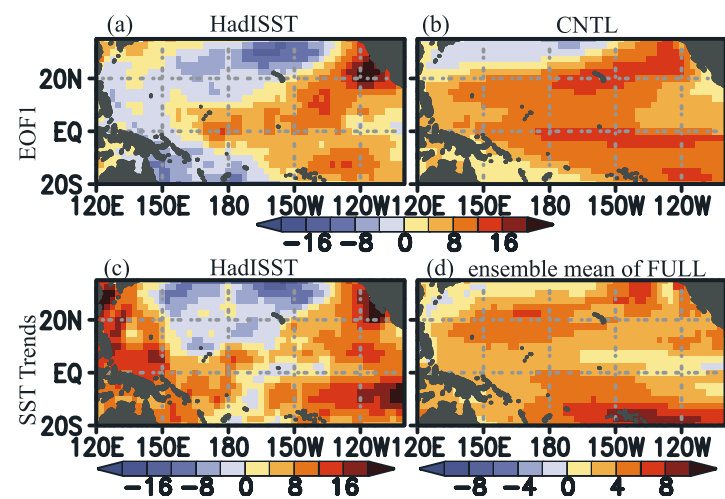

Figure 1. (Top) First EOF of the low-pass filtered, annual mean SST anomalies $\left(10^{-2}{ }^{\circ} \mathrm{C}\right.$ per standard deviation $)$ in the tropical and subtropical Pacific $\left(120^{\circ} \mathrm{E}-100^{\circ} \mathrm{W}, 20^{\circ} \mathrm{S}-\right.$ $35^{\circ} \mathrm{N}$ ) for $1951-2000$ in (a) the HadISST and (b) the CNTL run. The linear trends have been removed in advance from the HadISST data. They explain $53 \%$ and $62 \%$ of total variances, respectively. (Bottom) 1951-2000 linear trends of SST anomalies $\left(10^{-2}{ }^{\circ} \mathrm{C}\right.$ per decade) in (c) the HadISST and (d) the FULL ensemble average.

[Lefohn et al., 1999; T. Nozawa and J. Kurokawa, manuscript in preparation, 2005], alterations of stratospheric and tropospheric ozone [Randel and Wu, 1999; Sudo et al., 2002], and land use change [Hirabayashi et al., 2005]. The last simulation includes both natural and anthropogenic forcing. Each of these three simulations, referred to as NTRL, ANTH, and FULL, respectively, consists of four ensemble runs with initial conditions taken at 100-yr intervals from a stable 1400-yr pre-industrial control simulation (CNTL).

[8] We analyze the annual mean SST in the Pacific. The observed dataset compared with the CGCM simulations is SST data of HadISST [Rayner et al., 2003] on a $1^{\circ} \times 1^{\circ}$ grid. All observational and numerical model data are bi-linearly interpolated onto a $2.5^{\circ} \times 2.5^{\circ}$ grid. Additional analyses using another observational SST dataset, ERSST [Smith and Reynolds, 2004], confirm the results presented below (not shown). Although the period analyzed is $1870-$ 2000 , our analysis is focused mainly on the period $1951-$ 2000 when anthropogenic external forcing is large [IPCC, 2001], and the observational data is relatively reliable.

\section{Results}

[9] The top two panels of Figure 1 show the spatial structure of DENSO in HadISST for 1951-2000, together with that in the CNTL. The DENSO patterns are defined as the leading empirical orthogonal function (EOF) of annual mean SST anomalies in the subtropical and tropical Pacific $\left(120^{\circ} \mathrm{E}-100^{\circ} \mathrm{W}, 20^{\circ} \mathrm{S}-35^{\circ} \mathrm{N}\right)$. Before we perform the EOF analysis, we first extracted the internal variability from the observations by the removal of the external forcing influence via a least square linear fit. Interannual ENSO and other shorter time scale variability were also reduced by a simple 1-2-3-4-3-2-1 running-mean filter. The structure of the observed signal shows a wedge-shaped positive center of action in the central-eastern subtropical and tropical Pacific. The CGCM displays a wedge-shaped signal similar to the observational pattern, although the centers of action in the tropics are biased to the west with respect to those in the observations. Such a distortion is also found in other state of the art models [e.g., Yukimoto et al., 2000]. The power spectrum of the temporal coefficient of DENSO in the model shows a peak period around 20-30 years, which is similar to that in the observations reported by Minobe [1999] (not shown). Linear trend maps of SST during the 1951-2000 period in the observations and the ensemble mean of FULL are displayed in the bottom two panels of Figure 1. Overall, the trend patterns resemble the structure of DENSO in both the observation and the FULL forced simulations. Note that as in the observations, DENSO exhibits a positive trend in FULL.

[10] Observational and CGCM temporal coefficients of DENSO (DENSOIs) are computed by projecting the SST anomalies over the regions $160^{\circ} \mathrm{E}-100^{\circ} \mathrm{W}, 20^{\circ} \mathrm{S}-35^{\circ} \mathrm{N}$ and $120^{\circ} \mathrm{E}-100^{\circ} \mathrm{W}, 20^{\circ} \mathrm{S}-35^{\circ} \mathrm{N}$, respectively, where the tropical and subtropical DENSO signals are large, onto the first EOF patterns shown in Figures $1 \mathrm{a}$ and $1 \mathrm{~b}$, respectively. These regions are chosen to avoid underestimating the variance of the simulated DENSOI due to the aforementioned bias of the simulated DENSO structure. However, when the simulated DENSOI is defined over the region used for the observation, the finding presented below does not change. At first, standard deviations $(\sigma)$ of natural DENSOI variability estimated from the detrended observational SST for

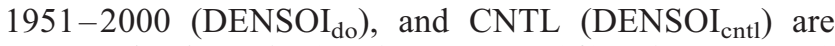
compared. The ratio $\left(\sigma\right.$ of $\left.\mathrm{DENSOI}_{\mathrm{cnt}}\right) /\left(\sigma\right.$ of $\left.\mathrm{DENSOI}_{\mathrm{do}}\right)$ is 0.9 , and an $F$ test implies that there is no significant disagreement between the variability in $\mathrm{DENSOI}_{\mathrm{do}}$ and DENSOI $_{\text {cntl }}$ at the $10 \%$ level. Here the effective sample

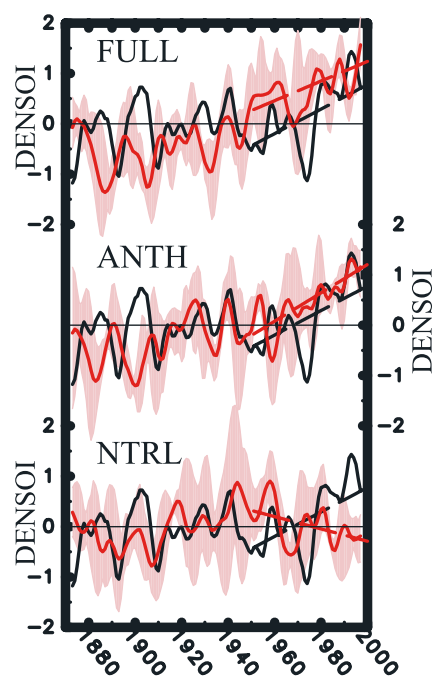

Figure 2. Black and red solid lines show the DENSOIs for the HadISST and the ensemble averages of the model runs, respectively. SST anomalies are defined as the deviations from the 1870-2000 period mean. The DENSOIs are normalized (see text for the detail), and are 1-2-3-4-3-2-1 running-mean filtered. Red shading shows the maximumminimum range of the 4 runs. Black and red dashed lines indicate the 1951-2000 period least-square linear regressions of the DENSOIs for the observations and the ensemble averages of the model runs, respectively. 


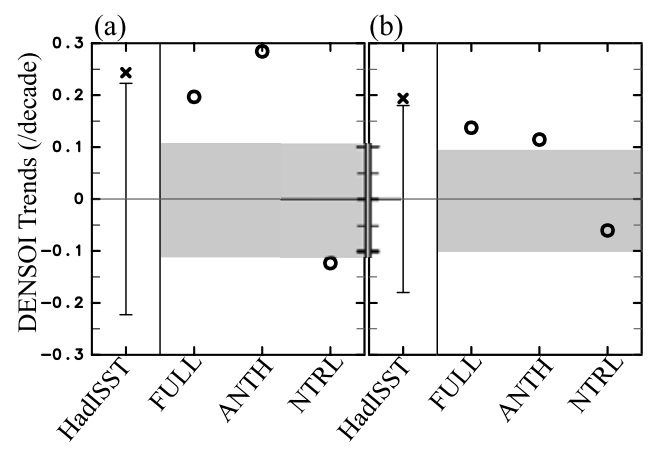

Figure 3. (a) The 1951-2000 linear trends of the DENSOI (decade ${ }^{-1}$ ) are shown for the ensemble averages of the model runs (circles) and the observations (cross). The error bar is the $5-95 \%$ natural variation range of a single $50-y r$ trend. Shading indicates the 5-95\% natural range of trends for ensemble average of four 50-yr segments (see text for the detail). (b) Same as panel (a), except that the DENSOIs are computed by projecting the SST anomalies, from which the Pacific-wide annual means have been removed in advance, onto the DENSO patterns.

sizes $\left(N_{\text {eff }}\right)$ are estimated as $2\left(\right.$ DENSOI $\left._{\mathrm{do}}\right)$ and 49 (DEN$\left.\mathrm{SOI}_{\text {cntl }}\right)$ by using the approximation $N_{\text {eff }}=N(1-r) /(1+r)$, where $N$ is the full sample size, and $r$ is the lag -1 autocorrelation coefficient of DENSOI [Wilks, 1995]. Figure 2 shows the DENSOIs for the observations and the ensemble averages of the CGCM runs, each of which is normalized by the $\sigma$ of $\mathrm{DENSOI}_{\mathrm{do}}$ and $\mathrm{DENSOI}_{\text {cntt. It }}$ is noteworthy that the observational DENSOI includes a positive linear trend after the 1950s. The ensemble mean of FULL experiments reproduces a positive linear trend. The ANTH and NTRL ensemble means show upward and slight downward trends, respectively. These results suggest that anthropogenic forcing promotes the positive trend in the FULL that resembles the observation.

[11] Statistical tests are carried out to assess the likelihood that the observed 1951-2000 upward trend could be considered to be a part of natural variations, and the possibility that the positive trend is attributable to the anthropogenic causes. The cross in Figure 3a indicates the 1951-2000 trend of the observed DENSOI. The three circles show the corresponding 50-yr trends of DENSOIs in the ensemble-mean of FULL, ANTH, and NTRL, respectively. The error bars indicate the 5-95\% natural variation ranges around 0 for a single run as evaluated using CNTL, and the shading is that for an ensemble average of 4 runs. The observed trend is clearly outside the $5-95 \%$ range. Significant differences from the natural range are evident in both the FULL and ANTH signals, but not in the NTRL. It is therefore concluded that, during the second half of the 20th century, the unusually large upward trend identified in the FULL forced response in this CGCM, and plausibly in nature as well, is attributed to the anthropogenic agents. The error bar is computed here by using $4950-y r$ long segments extracted from the $1400 \mathrm{yr}$ CNTL integration. The shading is estimated by random resampling of 4 members of 50-yr segments from the 49 samples of the CNTL.
[12] The attribution analysis is also applied to DENSOIs computed by projecting the SST anomalies, from which the annual mean Pacific-wide $\left(120^{\circ} \mathrm{E}-100^{\circ} \mathrm{W}, 20^{\circ} \mathrm{S}-60^{\circ} \mathrm{N}\right)$ mean anomalies have been removed in advance, onto the DENSO patterns (Figure 3b). There is no change in the finding. The annual mean Pacific-wide mean anomalies include positive trends for the observations, the FULL, and the ANTH (not shown). Although the magnitudes of the positive DENSOI trends decrease for the observations, the FULL, and the ANTH, they are outside the 5-95\% natural variation range. Therefore the aforementioned results can be assured not to be affected by the general warming.

[13] The observed 1901-1950 variability of DENSOI including the 1940s negative shifts [Zhang et al., 1997; Minobe, 1997; Mantua et al., 1997] is not successfully simulated. During the early and middle periods of 20th century (1901-1950 and 1926-1975), the DENSOI trend in the observation falls within the natural variation range. This result suggests that natural internal variation is more important for the fluctuation of DENSO in these periods than external forcings, although the significant anthropogenic influence on DENSO is identified in the late part of the 20th century.

\section{Summary}

[14] The simulation using the CCSR/NIES/FRCGC CGCM (MIROC) with realistic anthropogenic and natural external forcing reproduces the observed upward trend of DENSO during the second half of the 20th century. A comparison of the observations and the model suggests that: (1) the observed trend is larger than that expected due to purely natural fluctuations; (2) anthropogenic forcing is the main factor inducing this unusually large signal. These results are consistent with that of Knutson and Manabe [1998], who examined a CGCM experiment forced by simpler anthropogenic forcing (GHGs and direct effect of sulfate aerosol).

[15] We also performed a future climate projection for the 2001-2100 period by integrating MIROC under the IPCC SRES A1B emissions scenario [IPCC, 2000]. The DENSO index continues to increase during the 21 st century (not shown). Although predictions of the future state of the tropical Pacific are still uncertain [Collins and the CMIP Modelling Groups, 2005], comparing the late 20th century DENSO trends for the observations and the simulations may enable us to constrain the 21 st century predictions, i.e., an El Niño-like SST warming is suggested to be more probable than La Niña-like climate changes.

[16] Since there may still be uncertainties due to the incompleteness of the model, multi-model intercomparisons would be helpful to achieve a more robust evaluation. It remains to be determined how the anthropogenic forcing excites the DENSO trend.

[17] Acknowledgments. The authors wish to thank the K-1 project members for their support and discussion. We also thank Simon A. Crooks, Regis Bros, two anonymous reviewers, and the editor, Naohiro Yoshida for their helpful comments which greatly improved the manuscript. This work was supported by the Research Revolution 2002 (RR2002) or Kyousei project of the Ministry of Education, Culture, Sports, Science and Technology, by the Core Research for Evolutional Science and Technology (CREST) of the Japan Science and Technology Agency, and by the Global 
Environment Research Fund (GERF) of the Ministry of the Environment of Japan. The Earth Simulator and a NEC SX-6 at NIES were used to perform the CGCM simulations.

\section{References}

Barnett, T. P., D. W. Pierce, and R. Schnur (2001), Detection of anthropogenic climate change in the world's oceans, Science, 292, 270-274.

Collins, M., and the CMIP Modelling Groups (2005), El Niño- or La Niñalike climate change?, Clim. Dyn., 24, 89-104.

Deser, C., A. S. Phillips, and J. W. Hurrell (2004), Pacific interdecadal climate variability: Linkages between the tropics and North Pacific during boreal winter since 1900, J. Clim., 17, 3109-3124.

Folland, C. K., D. E. Parker, A. W. Colman, and R. Washington (1999) Large scale modes of ocean surface temperature since the late nineteenth century, in Beyond El Niño: Decadal and Interdecadal Climate Variability, edited by A. Navarra, pp. 73-102, Springer, New York

Gillett, N. P., H. F. Graf, and T. J. Osborn (2003), Climate change and the NAO, in The North Atlantic Oscillation: Climatic Significance and Environmental Impact, Geophys. Monogr. Ser., vol. 134, edited by J. Hurrell et al., pp. 193-209, AGU, Washington, D. C.

Hirabayashi, Y., S. Kanae, and T. Oki (2005), A 100-year (1901-2000) global retrospective estimation of terrestrial water cycle, J. Geophys. Res., 110, D19101, doi:10.1029/2004JD005492.

Intergovernmental Panel on Climate Change (IPCC) (2000), Special Report on Emissions Scenarios, edited by N. Nakicenovic and R. Swart, 599 pp. Cambridge Univ. Press, New York.

IPCC (2001), Climate Change 2001: The Science of Climate Change, edited by J. T. Houghton et al., 944 pp., Cambridge Univ. Press, New York.

Johns, T. C., et al. (2003), Anthropogenic climate change for 1860 to 2100 simulated with the HadCM3 model under updated emissions scenarios, Clim. Dyn., 20, 583-612.

K-1 Model Developers (2004), K-1 coupled model (MIROC) description, K-1 Tech. Rep. 1, edited by H. Hasumi and S. Emori, 34 pp., Cent. for Clim. Syst. Res., Univ. of Tokyo, Tokyo. (Available at http://www.ccsr. u-tokyo.ac.jp/kyosei/hasumi/MIROC/tech-repo.pdf)

Knutson, T. R., and S. Manabe (1998), Model assessment of decadal variability and trends in the tropical Pacific Ocean, J. Clim., 11, 2273-2296.

Lean, J., J. Beer, and R. Bradley (1995), Reconstruction of solar irradiance since 1610: Implications for climate change, Geophys. Res. Lett., 22 3195-3198

Lefohn, A. S., J. D. Husar, and R. B. Husar (1999), Estimating historical anthropogenic global sulfur emission patterns for the period 1850-1990, Atmos. Environ., 33, 3435-3444.

Livezey, R. E., and T. M. Smith (1999), Covariability of aspects of North American climate with global sea surface temperatures on interannual to interdecadal timescales, J. Clim., 12, 289-302.

Mantua, N. J., S. R. Hare, Y. Zhang, J. M. Wallace, and R. C. Francis (1997), A Pacific interdecadal oscillation with impacts on salmon production, Bull. Am. Meteorol. Soc., 78, 1069-1079.

Minobe, S. (1997), A 50-70 year climate oscillation over the North Pacific and North America, Geophys. Res. Lett., 24, 683-686.
Minobe, S. (1999), Resonance in bidecadal and pentadecadal climate oscillations over the North Pacific: Role in climatic regime shifts, Geophys. Res. Lett., 26, 855-858.

Moron, V., R. Vautard, and M. Ghil (1998), Trends, interdecadal and interannual oscillations in global sea surface temperatures, Clim., $545-569$.

Nitta, T., and S. Yamada (1989), Recent warming of tropical sea surface temperature and its relationship to the Northern Hemisphere circulation, J. Meteorol. Soc. Jpn., 67, 375-383.

Parker, D. E., P. D. Jones, C. K. Folland, and A. Bevan (1994), Interdecadal changes of surface temperature since the late nineteenth century, J. Geophys. Res., 99, 14,272-14,399.

Randel, W. J., and F. Wu (1999), A stratospheric ozone trends data set for global modeling studies, Geophys. Res. Lett., 26, 3089-3092.

Rayner, N. A., D. E. Parker, E. B. Horton, C. K. Folland, L. V. Alexander, D. P. Rowell, E. C. Kent, and A. Kaplan (2003), Global analyses of sea surface temperature, sea ice, and night marine air temperature since the late nineteenth century, J. Geophys. Res., 108(D14), 4407, doi:10.1029/ 2002JD002670.

Sato, M., J. E. Hansen, M. P. McCormick, and J. B. Pollack (1993), Stratospheric aerosol optical depths, 1850-1990, J. Geophys. Res., 98, 22,987-22,994.

Smith, T. M., and R. W. Reynolds (2004), Improved extended reconstruction of SST (1854-1997), J. Clim., 17, 2466-2477.

Sudo, K., M. Takahashi, J. Kurokawa, and H. Akimoto (2002), CHASER: A global chemical model of the troposphere: 1. Model description, J. Geophys. Res., 107(D17), 4339, doi:10.1029/2001JD001113.

Tett, S. F. B., P. A. Stott, M. R. Allen, W. J. Ingram, and J. F. B. Mitchell (1999), Causes of twentieth-century temperature change near the Earth's surface, Nature, 399, 569-572.

Trenberth, K. E., and T. J. Hoar (1996), The 1990-1995 El Niño Southern Oscillation event: Longest on record, Geophys. Res. Lett, 23, 57-60.

Wilks, D. S. (1995), Statistical Methods in the Atmospheric Sciences, 468 pp., Elsevier, New York.

Yu, B., and G. J. Boer (2002), The roles of radiation and dynamical processes in the El Niño-like response to global warming, Clim. Dyn., 19, 539-553.

Yukimoto, S., M. Endoh, Y. Kitamura, A. Kitoh, T. Motoi, and A. Noda (2000), ENSO-like interdecadal variability in the Pacific Ocean as simulated in a coupled general circulation model, J. Geophys. Res., 105, $13,945-13,963$.

Zhang, Y., J. M. Wallace, and D. S. Battisti (1997), ENSO-like interdecadal variability: 1900-93, J. Clim., 10, 1004-1020.

M. Kimoto, Center for Climate System Research, University of Tokyo, Kashiwa 277-8568, Japan.

T. Nozawa and H. Shiogama, National Institute for Environmental Studies, Tsukuba, Ibaraki 305-8506, Japan. (shiogama.hideo@nies.go.jp)

M. Watanabe, Faculty of Environmental Earth Science, Hokkaido University, Sapporo 060-0808, Japan. 